\title{
Predictors of betel quid chewing behavior and cessation patterns in
} Taiwan aborigines

\author{
Chin-Feng Lin ${ }^{1,2,3}$, Jung-Der Wang1, Ping-Ho Chen ${ }^{4}$, Shun-Jen Chang5, Yi- \\ Hsin Yang ${ }^{6,7}$ and Ying-Chin Ko*4,5
}

\begin{abstract}
Address: ${ }^{1}$ Institute of Occupational Medicine and Industrial Hygiene, National Taiwan University, College of Public Health and Department of Internal Medicine, National Taiwan University Hospital, Taipei, Taiwan, ${ }^{2}$ Department of Health, Executive Yuan, Taiwan, ${ }^{3}$ Department of Public Health, Taipei Medical University, Taipei, Taiwan, ${ }^{4}$ Division of Environmental Health and Occupational Medicine, National Health Research Institutes, Kaohsiung 807, Taiwan, ${ }^{5}$ Department of Public Health, Faculty of Medicine, College of Medicine, Kaohsiung Medical University, Kaohsiung, Taiwan, ${ }^{6}$ Graduate Institute of Oral Health Sciences, College of Dental Medicine, Kaohsiung Medical University, Kaohsiung, Taiwan and ${ }^{7}$ Statistical Analysis Laboratory, Department of Clinical Research, Kaohsiung Medical University Chung-Ho Memorial Hospital, Taiwan
\end{abstract}

Email: Chin-Feng Lin - baliowl@mail.bali.doh.gov.tw; Jung-Der Wang - jdwang@ha.mc.ntu.edu.tw; Ping-Ho Chen - phchen@nhri.org.tw; Shun-Jen Chang - changsj@kmu.edu.tw; Yi-Hsin Yang - yihsya@kmu.edu.tw; Ying-Chin Ko* - ycko@nhri.org.tw

* Corresponding author

Published: 03 November 2006

BMC Public Health 2006, 6:271

0.1/86/|47|-2458-6-27|
Received: 27 March 2006

Accepted: 03 November 2006

This article is available from: http://www.biomedcentral.com/I47|-2458/6/27।

(C) 2006 Lin et al; licensee BioMed Central Ltd.

This is an Open Access article distributed under the terms of the Creative Commons Attribution License (http://creativecommons.org/licenses/by/2.0), which permits unrestricted use, distribution, and reproduction in any medium, provided the original work is properly cited.

\begin{abstract}
Background: Betel quid, chewed by about 600 million people worldwide, is one of the most widely used addictive substances. Cessation factors in betel quid chewers are unknown. The present study explores prevalence and the quit rate of betel quid chewing in Taiwan aborigines. Our goal was to delineate potential predictors of chewing cessation.

Methods: A stratified random community-based survey was designed for the entire aborigines communities in Taiwan. A total of 7144 participants were included between June 2003 and May 2004 in this study. Information on sociodemographic characteristics, such as gender, age, obesity, education years, marital status, ethnicity, and habits of betel quid chewing, smoking and drinking was collected by trained interviewers.

Results: The prevalence of betel quid chewers was $46.1 \%$. Betel quid chewing was closely associated with obesity $(\mathrm{OR}=1.6 \mathrm{I} ; 95 \% \mathrm{Cl}$ : $1.40-1.85)$. Betel quid chewers were most likely to use alcohol and cigarettes together. Quit rate of betel quid chewers was 7.6\%. Betel quid chewers who did not drink alcohol were more likely to quit (OR $=1.89 ; 95 \% \mathrm{Cl}$ : I.43-2.50). Alcohol use is a significant factor related to cessation of betel quid chewing, but smoking is not.

Conclusion: Taiwan aborigines have a high prevalence of betel quid chewers and a low quit rate. Alcohol use is strongly association with betel quid chewing. Efforts to reduce habitual alcohol consumption might be of benefit in cessation of betel quid chewing.
\end{abstract}

\section{Background}

Betel quid consumption is an addictive habit with psychoactive properties, used by an estimated 600 million people worldwide [1-4]. This practice is widespread in
Taiwan, with approximately two million habitual users (10\% of population) [5]. In 2004, the International Agency for Research on Cancer (IARC) declared chewing of betel quid, by itself, to be a Group 1 carcinogen and the 
areca nut to be, correspondingly, a Group 1 carcinogen [6]. Chewing betel quid independently contributes to the risk of oropharyngeal cancer [7-9], oral mucosal lesions [10], oral leukoplakia [11], oral submucous fibrosis (OSF) [11], liver cirrhosis [12], hepatocellular carcinoma (HCC) [13], diabetes mellitus [14] and adverse outcomes with use during pregnancy $[15,16]$. These pertinent health risks highlight the need for cessation of betel quid chewing. Indeed, betel quid chewing is a recognized public health problem in Taiwan; active strategies are necessary to reduce use.

Several factors influence betel quid chewing, including predisposition associated with ethnicity, demographic and psychosocial factors, its accessibility and public policy. Taiwan aborigines have an extensive history of betel quid use. Their habits are dictated by different social and cultural behaviors in both genders. The life expectancy of Taiwan aborigines is one decade lower than the general population [17] and the mortality rate and prevalence of chronic diseases, such as liver cirrhosis, oral cancer and renal failure, are two-to five-folds higher than rest of the Taiwanese population [18]. The estimated prevalence of betel quid chewing in Taiwan aborigines is comparably higher than rest of Taiwanese population (42\% for Taiwan aborigines; $6 \%$ for Taiwanese population)[5]. Despite studies to investigate the high prevalence of betel quid chewing in Taiwan aborigines, contributing factors and quit patterns between former and current chewers have not been documented. This report provides the first description of prevalence and patterns of cessation in Taiwan aborigines.

\section{Methods \\ Design}

A large-scale survey of substance use (betel quid, alcohol and cigarette) among Taiwan aborigines was completed. Data was obtained by interviewing participants in their communities between June 2003 and May 2004.

Approximately $86 \%$ of Taiwanese are descended from Han Chinese, whose ancestors migrated 400 years ago from Fukkien and Canton provinces [19]. Taiwan aborigines constitute approximately $2 \%$ of the population, rarely mix with Han Chinese and reside in isolated mountainous areas with their own language, customs and social organizations. Genetically, they are markedly different from Han Chinese [20]. There are twelve aborigines tribes in Taiwan and most live in fifty isolated communities. Very few Han Chinese live in aborigines communities unless they work in the community or married aborigines. Due to random sampling, about $9 \%$ of participants are Han Chinese. They provide a comparison between aborigines and non-aborigines, because they lived in the same community. A random sampling approach was used with these fifty communities, stratified by gender and age group ( $>=18$ years). According to our previous study, the prevalence of betel quid chewing is approximately $20 \%$. We randomly selected 150 to 200 persons via a household registry system in each community, obtaining 95\% confidence interval $(\mathrm{CI})$ within $\pm 3 \%$ [5]. The prevalence of betel quid chewing is between $1 \%$ and $50 \%$ in some areas, obtaining the prevalence of $95 \%$ CI between $\pm 1 \%$ and $5 \%$ [5]. The prevalence of betel quid chewing in Taiwan aborigines males and females is $42.1 \%$ and $19.2 \%$ respectively, among three tribes [5]. Each participant completed an interview questionnaire with trained nurses, fulfilling our target population of 9124 persons. Questionnaire contents included demographic characteristics, body morphology (height and weight), past and current histories of betel chewing, and cigarette and alcohol use. This study was approved by the Medical Associations for Indigenous People in Taiwan (No. 930010) and agreed by Department of Health, Executive Yuan (No. 0933500309).

\section{Data analysis}

\section{Dependent variables}

Separate analyses were conducted for betel quid chewing behavior and chewing cessation. The dichotomous dependent variable, betel quid chewing behavior, was coded as betel quid chewers (chewed at least once a week, irrespective of quantity) or never chewers (those who never chewed). The other dependent variable, betel quid chewing cessation, was coded as former chewers (those who quit chewing at least one year prior the survey) or current chewers (continual chewing habit). In addition, betel quid chewers included former chewers and current chewers.

\section{Independent variables}

Potential explanatory (independent) variables included gender, age, obesity, education, age commenced chewing (years), quids per day, marital status, ethnicity, alcohol consumption, and cigarette smoking. Taiwan aborigines status was classed into three groups, "Taiwan aborigines" when both parents were Taiwan aborigines, "mixed Taiwan aborigines" when one parent was Taiwan aborigines, and "non-Taiwan aborigines" when both parents were not Taiwan aborigines. Body mass index (BMI) was calculated as body weight in kilograms divided by square of body height in meters. Obesity was defined by BMI $\geq 27.8 \mathrm{~kg} /$ $\mathrm{m}^{2}$ for men and $\geq 27.3 \mathrm{~kg} / \mathrm{m}^{2}$ for women. Continuous variables, including age, education years, age commenced chewing, numbers chewed per day, were divided into two categories, above and below the median cut-off.

\section{Statistical analyses}

Data were entered into a spreadsheet and analyzed using Statistic Analysis Software (SAS release 8.2, Cary, NC, USA). Missing data were excluded. Crude odds ratios 
(OR) with 95\% CI were calculated. To control for potential confounding effects, statistically significant ORs were subsequently examined in the multiple logistic regression model to obtain adjusted OR (aOR). $P$ value less than 0.05 or a range of $95 \% \mathrm{CI}$ that did not include unity, were considered statistically significant.

\section{Results}

A total of 7326 participants completed our questionnaires from aborigines population of 9124 . The response rate was $80.3 \%$ (7326/9124). All participants were over 18 years of age (mean $45.3 \pm 17.0$ years). Factors associated with a betel quid chewing habit are shown in Table 1. The prevalence of betel quid chewers (current and former chewers) was $46.1 \%$ of total subjects (3291/7144), with the males (53.2\%, 2033/3824) higher than females $(37.9 \%, 1258 / 3320) p<0.05$. After adjustment for all factors with a logistic regression model, factors most associated with betel chewing were male, obesity, less education, married status, Taiwan aborigines, mixed-Taiwan aborigines, drinking alcohol and smoking cigarettes $(p<0.05)$. It was noteworthy that the adjusted OR stratified by age showed that older group ( $>=45$ years) was less likely to have chewing habits.

Table 2 depicts the distribution of demographic characteristics, comparing former chewers to current chewers. The 251 former chewers account for $7.6 \%$ in betel quid chewers $(251 / 3291)$. The quit rate for males is $8.2 \%(167 /$ $2033)$ and $6.7 \%(84 / 1258)$ for females. In the unadjusted analysis, the crude OR showed those who were older, non-Taiwan aborigines, chewing a smaller amount of quids per day (quids $<=10$ ) and consuming no alcohol to be most likely to quit their chewing habits. Adjusting associations with logistic regression, those older than 45 years and with no alcohol consumption habits had a significantly higher quit rate $(p<0.05)$. However, the Taiwan aborigines were still less likely to quit chewing habits.

Prevalence of current chewers by ethnicity and gender (Table 3), compared to total subjects was $42.6 \%$ (3040/ 7144 ) and of current betel quid chewers, males and

Table I: Sociodemographic characteristics and betel quid chewing behaviors $(N=7 \mid 44)$

\begin{tabular}{|c|c|c|c|c|c|c|}
\hline & \multicolumn{2}{|c|}{ Betel quid chewers $(N=3291)$} & \multicolumn{2}{|c|}{ Never chewers $(\mathrm{N}=3853)$} & \multirow[t]{2}{*}{$\mathrm{OR}^{\mathrm{b}}(95 \% \mathrm{Cl})$} & \multirow[t]{2}{*}{$\mathrm{aOR}^{\mathrm{c}}(95 \% \mathrm{Cl})$} \\
\hline & $\mathrm{N}$ & $(\%)^{\mathrm{a}}$ & $N$ & $(\%)^{\mathrm{a}}$ & & \\
\hline \multicolumn{7}{|l|}{ Gender* } \\
\hline Male & 2033 & $(53.2)$ & $179 \mid$ & $(46.8)$ & $1.86(1.69-2.05) \dagger$ & $1.14(1.01-1.30) \dagger$ \\
\hline Female & 1258 & (37.9) & 2062 & $(62.1)$ & 1.00 & 1.0 \\
\hline \multicolumn{7}{|l|}{ Age (years)* } \\
\hline$>=45$ & 1582 & $(48.0)$ & 1716 & $(52.0)$ & $1.15(1.05-1.27) \dagger$ & $0.84(0.72-0.97) \dagger$ \\
\hline$<45$ & 1709 & $(44.4)$ & 2137 & $(55.6)$ & 1.00 & 1.0 \\
\hline \multicolumn{7}{|l|}{ Obesity* } \\
\hline Yes & 800 & $(55.8)$ & 633 & $(44.2)$ & $1.63(1.45-1.84) \dagger$ & $1.61(1.40-1.85) \dagger$ \\
\hline No & 2491 & $(43.6)$ & 3220 & $(56.4)$ & 1.00 & 1.0 \\
\hline \multicolumn{7}{|l|}{ Education (years)* } \\
\hline$<=6$ & 1709 & $(52.8)$ & $|53|$ & $(47.3)$ & $1.64(1.49-1.80) \dagger$ & $2.02(1.75-2.34) \dagger$ \\
\hline$>6$ & 1582 & $(40.5)$ & 2322 & $(59.5)$ & 1.00 & 1.0 \\
\hline \multicolumn{7}{|l|}{ Marital status* } \\
\hline Married & 2661 & $(49.1)$ & 2762 & $(50.9)$ & $1.69(1.51-1.89) \dagger$ & $1.5 \mathrm{I}(1.30-1.75) \dagger$ \\
\hline Single & 602 & $(36.3)$ & 1057 & $(63.7)$ & 1.00 & 1.0 \\
\hline \multicolumn{7}{|l|}{ Ethnicity* } \\
\hline Taiwan aborigines & 3018 & $(49.7)$ & 3059 & $(50.3)$ & $5.30(4.28-6.56) \dagger$ & $3.83(3.01-4.89) \dagger$ \\
\hline Mixed-Taiwan aborigines & 128 & $(43.1)$ & 169 & $(56.9)$ & $4.07(2.98-5.54) \dagger$ & $3.01(2.09-4.34) \dagger$ \\
\hline Non-Taiwan aborigines & 106 & $(15.7)$ & 569 & (84.3) & 1.00 & 1.0 \\
\hline \multicolumn{7}{|l|}{ Alcohol consumption* } \\
\hline Yes & 2480 & $(66.9)$ & 1225 & $(33.1)$ & $7.05(6.33-7.84) \dagger$ & $4.50(4.00-5.07) \dagger$ \\
\hline No & 731 & $(22.3)$ & 2545 & (77.7) & 1.00 & 1.0 \\
\hline \multicolumn{7}{|l|}{ Cigarette smoking* } \\
\hline Yes & $182 \mid$ & $(66.8)$ & 906 & $(33.2)$ & $4.28(3.86-4.74) \dagger$ & $3.03(2.66-3.45) \dagger$ \\
\hline No & 1363 & $(32.0)$ & 2899 & $(68.0)$ & 1.00 & 1.0 \\
\hline
\end{tabular}

* Significant difference in prevalence of betel quid chewing by Chi-square analysis $(p<0.05)$.

$\dagger$ Significant difference by logistic regression model $(p<0.05)$.

a May not total $100 \%$ due to rounding.

b Odds ratios (OR) refer to risk of betel quid chewers (including former chewers and current chewers) versus never chewers according to each variable. $O R>I$ indicates a higher likelihood of being a betel quid chewer.

c aOR: adjusted odds ratio for sex, age (years), obesity, education (years), marital status, ethnicity, alcohol consumption, and cigarette smoking by logistic regression model; $95 \% \mathrm{Cl}$ : $95 \%$ confidence interval. 
Table 2: Demographic characteristics in the cessation of betel quid chewing. $(\mathbf{N}=329 \mathrm{I})$

\begin{tabular}{|c|c|c|c|c|c|c|}
\hline & \multicolumn{4}{|c|}{ Betel quid chewers } & \multirow{3}{*}{$\mathrm{OR}^{\mathrm{b}}(95 \% \mathrm{Cl})$} & \multirow{3}{*}{$\mathrm{aOR}^{\mathrm{c}}(95 \% \mathrm{Cl})$} \\
\hline & \multicolumn{2}{|c|}{ Former chewers $(N=25 \mathrm{I})$} & \multicolumn{2}{|c|}{ Current chewers $(N=3040)$} & & \\
\hline & $\mathrm{N}$ & $(\%)^{\mathrm{a}}$ & $N$ & $(\%)^{\mathrm{a}}$ & & \\
\hline \multicolumn{7}{|l|}{ Gender } \\
\hline Male & 167 & $(8.2)$ & 1866 & (9l.8) & $1.25(0.95-1.64)$ & - \\
\hline Female & 84 & (6.7) & 1174 & (93.3) & 1.00 & \\
\hline \multicolumn{7}{|l|}{ Age $(y r s)^{*}$} \\
\hline$>=45$ & 157 & $(9.9)$ & 1425 & $(90.1)$ & $1.89(1.45-2.47) \dagger$ & I.84(I.40-2.42) † \\
\hline$<45$ & 94 & (5.5) & 1615 & (94.5) & 1.00 & 1.00 \\
\hline \multicolumn{7}{|l|}{ Obesity } \\
\hline Yes & 58 & $(7.3)$ & 742 & $(92.8)$ & $0.93(0.69-1.26)$ & - \\
\hline No & 193 & (7.8) & 2298 & $(92.3)$ & 1.00 & \\
\hline \multicolumn{7}{|l|}{ Education (years) } \\
\hline$<=6$ & 137 & $(8.0)$ & 1572 & $(92.0)$ & I.12(0.87-I.45) & - \\
\hline$>6$ & 114 & (7.2) & 1468 & $(92.8)$ & 1.00 & \\
\hline \multicolumn{7}{|c|}{ Age commenced chewing (years) } \\
\hline$>=20$ & 166 & $(8.0)$ & 1923 & $(92.1)$ & $1.13(0.87-1.49)$ & - \\
\hline$<20$ & 85 & (7.1) & 1117 & $(92.9)$ & 1.00 & \\
\hline \multicolumn{7}{|l|}{ Quids per day* } \\
\hline$<=10$ & 134 & $(8.8)$ & 1397 & $(91.3)$ & $1.34(1.04-1.74) \dagger$ & $1.24(0.95-1.62)$ \\
\hline$>10$ & 117 & $(6.7)$ & 1643 & $(93.4)$ & 1.00 & 1.00 \\
\hline \multicolumn{7}{|l|}{ Marital status } \\
\hline Married & 213 & $(8.0)$ & 2448 & $(92.0)$ & $1.33(0.93-1.91)$ & - \\
\hline Single & 37 & (6.2) & 565 & (93.9) & 1.00 & \\
\hline \multicolumn{7}{|l|}{ Ethnicity* } \\
\hline Taiwan aborigines & 218 & $(7.2)$ & 2800 & $(92.8)$ & $0.36(0.21-0.60) \dagger$ & $0.40(0.24-0.68) \dagger$ \\
\hline Mixed-Taiwan aborigines & 9 & $(7.0)$ & 119 & $(93.0)$ & $0.35(0.15-0.80) \dagger$ & $0.47(0.20-1.11)$ \\
\hline Non-Taiwan aborigines & 19 & $(17.9)$ & 87 & $(82.1)$ & 1.00 & 1.00 \\
\hline \multicolumn{7}{|l|}{ Alcohol consumption* } \\
\hline No & 91 & $(12.5)$ & 640 & $(87.6)$ & $2.10(1.60-2.76) \dagger$ & $1.89(1.43-2.50) \dagger$ \\
\hline Yes & 157 & $(6.3)$ & 2323 & (93.7) & 1.00 & 1.00 \\
\hline \multicolumn{7}{|l|}{ Cigarette smoking } \\
\hline No & 97 & $(7.1)$ & 1266 & $(92.9)$ & $0.89(0.68-1.16)$ & - \\
\hline Yes & 145 & (8.0) & 1676 & $(92.0)$ & 1.00 & \\
\hline
\end{tabular}

* Significant difference in the prevalence of former and current chewers by Chi-square analysis $(p<0.05)$

† Significant difference by logistic regression model $(P<0.05)$.

a May not total $100 \%$ due to rounding.

b Odds ratios (OR) refer to the risk of former chewers versus current chewers according to each variable. OR > I indicates a higher likelihood of being a former chewer (quit chewing).

c aOR: adjusted odds ratio for age (years), quids per day, ethnicity and alcohol consumption by logistic regression model; $95 \% \mathrm{Cl}: 95 \%$ confidence interval.

females were $48.8 \%$ and $35.4 \%$, respectively. Ethnicity was classified into five groups: both parents are Taiwan aborigines, only father is Taiwan aborigines, only mother is Taiwan aborigines, non-Taiwan aborigines, and others. The highest prevalence of current male chewers was in those whose mother was Taiwan aborigines (55.7\%; 64/ 115). In females, the highest prevalence was among those whose both parents were Taiwan aborigines (39.3\%; $1115 / 2834$ ). The quit rate of betel quid chewing by ethnicity and sex is summarized in Table 4 . Excluding others, the highest quit rate $(18.5 \%)$ was seen in non-Taiwan aborigines males. In contrast, the lowest quit rate was $3.5 \%$ among females whose mother is Taiwan aborigines.
Independent effects of alcohol consumption, cigarette smoking and betel quid chewing on cessation were evaluated by stratifying alcohol and cigarette use across the behavior of betel quid chewing (Table 5). For the nondrinker and nonsmoker who chewed betel quid before, the likelihood of cessation increased 1.76-fold over those who drink and smoke. Likelihood was also significantly increased for betel quid chewers who did not drink, but had smoking habits (OR $=2.19$; 95\% CI: $1.48-3.26$ ). After controlling for other factors, similar cessation patterns were observed in the betel quid chewers who had no drinking habits, but did smoke (aOR $=1.99$; 95\% CI: 1.32 $-2.99)$. 
Table 3: Prevalence rate of current betel quid chewers $(N=3040)$ by ethnicity and by gender

\begin{tabular}{|c|c|c|}
\hline & \multicolumn{2}{|c|}{ Prevalence rate of current betel quid chewers (\%) } \\
\hline & Males & Females \\
\hline \multicolumn{3}{|l|}{ Ethnicity } \\
\hline Both parents are Taiwan aborigines & $1685 / 3243(52.0)$ & $1115 / 2834(39.3)$ \\
\hline Only father is Taiwan aborigines & $22 / 52(42.3)$ & $5 / 36(13.9)$ \\
\hline Only mother is Taiwan aborigines & $64 / 115(55.7)$ & $28 / 94(29.8)$ \\
\hline Non-Taiwan aborigines & $75 / 360(20.8)$ & $12 / 315(3.8)$ \\
\hline Others & $20 / 54(37.0)$ & $|4 / 3|(45.2)$ \\
\hline Subtotal & I866/3824 (48.8) & $1174 / 3320(35.4)$ \\
\hline Total & $3040 / 7 \mid 44(42.7)$ & \\
\hline
\end{tabular}

\section{Discussion}

Research into betel quid chewing and cessation factors is limited. In this large survey, the sociodemographic factors in betel quid chewing behavior and cessation patterns in Taiwan aborigines were examined. Compared to those who never chewed, betel quid chewers were more likely to be male, obese, of lower education, married, Taiwan aborigines or mixed Taiwan aborigines, a drinker and smoker. On the contrary, subjects who were older were less likely to be betel quid chewers.

This study is more reliable than past studies in determining prevalence and betel chewing association factors in Taiwan aborigines, because a randomized and systematic surveillance-style approach was adopted to recruit participants from their own communities.

There were more betel quid chewers among males than females in this study (aOR $=1.14 ; 95 \%$ CI: 1.01-1.30). This might be explained by the higher prevalence of chewing in Taiwanese males [5]. Taiwan aborigines have a higher prevalence of betel quid chewing than Han Chinese [5] and are more likely to be betel quid chewers than
non-Taiwan aborigines (aOR $=3.83 ; 95 \%$ CI: 3.01-4.89). In Taiwan, betel quid chewing is widespread; chewers are frequently alcohol drinkers and smokers. After adjusting for other factors, the prevalence of drinking and smoking habits was significantly higher in betel quid chewers than in those who never chewed.

Another important finding is that betel quid chewing is closely associated with obesity. Obesity is a recognized risk factor for chronic diseases, such as diabetes mellitus, cardiovascular diseases, and hypertension. According to previous studies, betel quid chewing can increase body mass index (BMI) or contribute to obesity [21-23] by the betel quid constituents (alkaloid, arecoline and arecaidine) as inhibitors of $\gamma$-aminobutyric acid (GABA) receptor $[4,24]$.

The present study is the first estimation of quit rates for betel quid chewing among Taiwan aborigines. Our findings indicate that cessation probability increases with older age group, non-Taiwan aborigines, and those who do not drink. Interestingly, another survey on smoking behavior showed a significantly positive association

Table 4: Quit rate of betel quid chewers $(N=329 I)$ by ethnicity and by gender

\begin{tabular}{lll}
\hline & & Quit rate of betel quid chewers (\%) \\
\cline { 2 - 3 } & Males & Females \\
\hline Ethnicity & & \\
Both parents are Taiwan aborigines & $138 / 1823(7.6)$ & $80 / 1195(6.7)$ \\
Only father is Taiwan aborigines & $1 / 23(4.4)$ & $1 / 6(16.7)$ \\
Only mother is Taiwan aborigines & $6 / 70(8.6)$ & $1 / 29(3.5)$ \\
Non-Taiwan aborigines & $17 / 92(18.5)$ & $2 / 14(14.3)$ \\
Others & $5 / 25(20)$ & $0 / 14(0)$ \\
Subtotal & $167 / 2033(8.2)$ & $84 / 1258(6.7)$ \\
\hline Total & $251 / 3291(7.6)$ &
\end{tabular}


Table 5: Effects of alcohol consumption and cigarette smoking on cessation

\begin{tabular}{|c|c|c|c|c|c|}
\hline & & \multicolumn{2}{|c|}{ Betel quid chewers } & \multirow[b]{2}{*}{$\mathrm{OR}(95 \% \mathrm{Cl})^{\mathrm{a}}$} & \multirow[b]{2}{*}{$\mathrm{aOR}(95 \% \mathrm{Cl})^{\mathrm{b}}$} \\
\hline & & Former chewers $(N=239)$ & Current chewers $(\mathrm{N}=2882)$ & & \\
\hline \multicolumn{6}{|c|}{$\begin{array}{l}\text { Alcohol } \\
\text { No }\end{array}$} \\
\hline & $\begin{array}{c}\text { Cigarette } \\
\text { No }\end{array}$ & 51 & 390 & $1.76(1.24-2.50) \dagger$ & $1.25(0.86-1.83)$ \\
\hline & $\begin{array}{c}\text { Cigarette } \\
\text { Yes }\end{array}$ & 38 & 233 & $2.19(1.48-3.26) \dagger$ & $1.99(1.32-2.99) \dagger$ \\
\hline \multicolumn{6}{|c|}{$\begin{array}{l}\text { Alcohol } \\
\text { Yes }\end{array}$} \\
\hline & $\begin{array}{c}\text { Cigarette } \\
\text { No }\end{array}$ & 45 & 847 & $0.72(0.50-1.02)$ & $0.59(0.40-1.86) \dagger$ \\
\hline & $\begin{array}{c}\text { Cigarette } \\
\text { Yes }\end{array}$ & 105 & 1412 & 1.00 & 1.00 \\
\hline
\end{tabular}

† Significant difference by logistic regression model $(p<0.05)$.

a Odds ratios (OR) refer to the risk of former chewers versus current chewers according to each variable. OR $>$ I indicates a higher likelihood of being a former chewer (quit chewing).

b aOR: adjusted odds ratio for age (years), quids per day, and ethnicity by logistic regression model; $95 \% \mathrm{Cl}$ : $95 \%$ confidence interval.

between smoking cessation and increased age [25]. We observed that former chewers comprise $7.6 \%$ of total users. Within this, Taiwan aborigines (7.2\%) and mixed Taiwan aborigines $(7.0 \%)$ had a lower quit rate than nonTaiwan aborigines $(17.9 \%, p<0.05)$. Apart from the Taiwan aborigines heritage, age group and use of betel quid with alcohol influenced the quit rate. Our study suggested that young Taiwan aborigines or mixed-Taiwan aborigines, who were also alcohol drinkers, found it more difficult to abstain from betel quid chewing. Dr. Wen et al. noted the combined effects of cigarette smoking and betel quid chewing in Han Chinese [26] and suggested that betel quid chewing should not to be considered as an isolated issue. Our results have shown the combined effect of betel quid chewing and alcohol consumption also existed in Taiwan aborigines. Therefore, cessation should be viewed conjointly with alcohol consumption.

Clearly, the highest prevalence of both chewing and of quitting chewing was seen in Taiwan aborigines males whose mother was Taiwan aborigines (Table 3 and Table 4). However, in Taiwan aborigines females, this consistent association was not obvious. We suggest that the likelihood of being a current or former chewer was higher in Taiwan aborigines males whose mother is Taiwan aborigines.

Our multivariate analyses noted that alcohol consumption was an independent factor in cessation (Table 5). For the nondrinkers and nonsmokers who chewed betel quid before, their cessation rate was higher than in those who had drinking and smoking habits. Nondrinkers with cigarette smoking had the highest cessation behavior, com- pared to those who have drinking and smoking habits, even after adjusting for covariates $(\mathrm{OR}=1.99 ; 95 \% \mathrm{CI}=$ $1.32-2.99)$. The cessation discrepancy between betel quid chewers with and without alcohol implies that alcohol not consumption have an additional effect on cessation [5]. The main outcome of our study is that efforts to encourage cessation of betel quid chewing will need to include efforts to reduce habitual alcohol consumption. In contrast, reducing cigarette smoking also serves as an important step in reducing betel quid chewing [26].

\section{Conclusion}

Taiwan aborigines have a high prevalence of betel quid chewing and a low quit rate. Betel quid chewing independently contributes to the likelihood of obesity. Alcohol usage is strongly related to betel quid chewing. Efforts to reduce betel quid chewing might benefit from a combined approach targeting both these habits.

\section{Competing interests}

The author(s) declare that they have no competing interests.

\section{Authors' contributions}

$\mathrm{CF}$ and JD carried out the studies, participated in the sequence alignment and drafted the manuscript. $\mathrm{PH}, \mathrm{SJ}$ and $\mathrm{YH}$ participated in the design of the study and performed the statistical analysis. YC led this study, and participated in its design and coordination and helped to complete the manuscript. All of the authors participated in the establishment of the system design, and all read and approved the manuscript. 


\section{Acknowledgements}

This study was supported by grants from Department of Health, Executive Yuan, Taiwan, R.O.C. (No. 0933500309). We are grateful to Dr. Allen MinJen Ko for correcting our manuscript.

\section{References}

I. Chu NS: Effects of Betel chewing on the central and autonomic nervous systems. Journal of Biomedical Science 200I, 8(3):229-236.

2. Gupta PC, Warnakulasuriya S: Global epidemiology of areca nut usage. Addiction Biology 2002, 7(I):77-83.

3. Chen MJ, Yang YH, Shieh TY: Evaluation of a self-rating screening test for areca quid abusers in Taiwan. Public Health 2002, I l 6(4): 195-200.

4. Boucher BJ, Mannan N: Metabolic effects of the consumption of Areca catechu. Addiction Biology 2002, 7(I): 103-II0.

5. Ko YC, Chiang TA, Chang SJ, Hsieh SF: Prevalence of betel quid chewing habit in Taiwan and related sociodemographic factors. Journal of Oral Pathological Medicine 1992, 2 I(6):26 I-264.

6. IARC: Betel-quid and areca-nut chewing and some areca-nutderived nitrosamines, IARC Monographs on the evaluation of carcinogenic risks to humans. 2004, 85: II-I8.

7. Ko YC, Huang YL, Lee CH, Chen MJ, Lin LM, Tsai CC: Betel quid chewing, cigarette smoking and alcohol consumption related to oral cancer in Taiwan. Journal of Oral Pathological Medicine 1995, 24( I 0):450-453.

8. Lu CT, Yen YY, Ho CS, Ko YC, Tsai CC, Hsieh CC, Lan SJ: A casecontrol study of oral cancer in Changhua County, Taiwan. Journal of Oral Pathological Medicine 1996, 25(5):245-248.

9. Lee KW, Kuo WR, Tsai SM, Wu DC, Wang WM, Fang FM, Chiang FY, Ho KY, Wang LF, Tai CF, Kao EL, Chou SH, Lee CH, Chai CY, Ko YC: Different impact from betel quid, alcohol and cigarette: risk factors for pharyngeal and laryngeal cancer. International Journal of Cancer 2005, I I 7(5):83 I-836.

10. Yang YH, Lee HY, Tung S, Shieh TY: Epidemiological survey of oral submucous fibrosis and leukoplakia in aborigines of Taiwan. Journal of Oral Pathological Medicine 200I, 30(4):2। 3-2I9.

I I. Lee CH, Ko YC, Huang HL, Chao YY, Tsai CC, Shieh TY, Lin LM: The precancer risk of betel quid chewing, tobacco use and alcohol consumption in oral leukoplakia and oral submucous fibrosis in southern Taiwan. British Journal of Cancer 2003, 88(3):366-372.

12. Tsai JF, Jeng JE, Chuang LY, Ho MS, Ko YC, Lin ZY, Hsieh MY, Chen SC, Chuang WL, Wang LY, Yu ML, Dai CY, Ho C: Habitual betel quid chewing as a risk factor for cirrhosis: a case-control study. Medicine (Baltimore) 2003, 82(5):365-372.

13. Tsai JF, Jeng JE, Chuang LY, Ho MS, Ko YC, Lin ZY, Hsieh MY, Chen SC, Chuang WL, Wang LY, Yu ML, Dai CY: Habitual betel quid chewing and risk for hepatocellular carcinoma complicating cirrhosis. Medicine (Baltimore) 2004, 83(3): I76-I87.

14. Tung TH, Chiu YH, Chen LS, Wu HM, Boucher BJ, Chen TH: A population-based study of the association between areca nut chewing and type $\mathbf{2}$ diabetes mellitus in men (Keelung Community-based Integrated Screening programme No. 2). Diabetologia 2004, 47(10): I776-1781.

15. Yang MS, Chang FT, Chen SS, Lee $\mathrm{CH}$, Ko YC: Betel quid chewing and risk of adverse pregnancy outcomes among aborigines in southern Taiwan. Public Health I999, I I3(4): |89- I 92.

16. Yang MJ, Chung TC, Yang MJ, Hsu TY, Ko YC: Betel quid chewing and risk of adverse birth outcomes among aborigines in eastern Taiwan. Journal Toxicology and Environmental Health Part A 200I, 64(6):465-472.

17. Ko YC, Liu BH, Hsieh SF: [Issues on aboriginal health in Taiwan]. The Kaohsiung Journal of Medical Sciences 1994, I 0(7):337-35 I.

18. Ko YC, Liu BH, Hsieh SF, Wang TN: [Cancer mortality analysis among aborigines in Taiwan]. The Kaohsiung Journal of Medical Sciences 1994, I0(7):379-391.

19. Department of Population. Consensus 1990: Census report of the Republic of China in Taiwan. Taipei, ROC. 1992

20. Bellwood P: The Austronesian dispersal and the origin of languages. Sci Am 1991, 265:70-75.

21. Mannan N, Boucher BJ, Evans SJ: Increased waist size and weight in relation to consumption of Areca catechu (betel-nut); a risk factor for increased glycaemia in Asians in east London. British Journal of Nutrition 2000, 83(3):267-275.
22. Strickland SS, Duffield AE: Anthropometric status and resting metabolic rate in users of the areca nut and smokers of tobacco in rural Sarawak. Annals of Human Biology 1997, 24(5):453-474.

23. Chang WC, Hsiao CF, Chang HY, Lan TY, Hsiung CA, Shih YT, Tai TY: Betel nut chewing and other risk factors associated with obesity among Taiwanese male adults. Int J Obes (Lond) 2006, 30(2):359-363.

24. Johnston GA, Krogsgaard-Larsen P, Stephanson A: Betel nut constituents as inhibitors of gamma-aminobutyric acid uptake. Nature 1975, 258(5536):627-628.

25. Manzoli L, Di Giovanni P, Dragani V, Ferrandino MG, Morano JP, Rauti I, Schioppa F, Romano F, Staniscia T: Smoking behaviour, cessation attempts and the influence of parental smoking in older adult women: a cross-sectional analysis from Italy. Public Health 2005, I I 9(8):670-678.

26. Wen CP, Tsai SP, Cheng TY, Chen CJ, Levy DT, Yang HJ, Eriksen MP: Uncovering the relation between betel quid chewing and cigarette smoking in Taiwan. Tobacco Control 2005, I4 Suppl I:il 6-22.

\section{Pre-publication history}

The pre-publication history for this paper can be accessed here:

http://www.biomedcentral.com/1471-2458/6/271/pre pub
Publish with Bio Med Central and every scientist can read your work free of charge

"BioMed Central will be the most significant development for disseminating the results of biomedical research in our lifetime. "

Sir Paul Nurse, Cancer Research UK

Your research papers will be:

- available free of charge to the entire biomedical community

- peer reviewed and published immediately upon acceptance

- cited in PubMed and archived on PubMed Central

- yours - you keep the copyright

Submit your manuscript here:

http://www.biomedcentral.com/info/publishing_adv.asp
BioMedcentral 